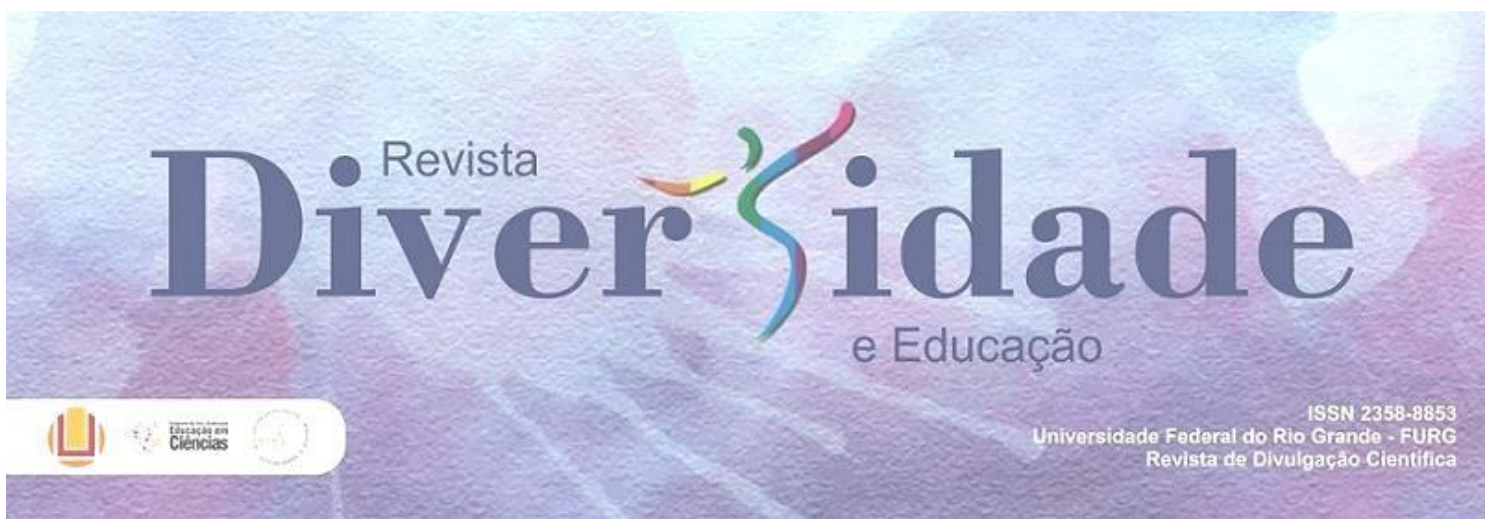

\title{
FORMAÇÃO DE MASCULINIDADES: ANÁLISE DAS RELAÇÕES PRESENTES EM UMA TURMA DE ESCOLA PÚBLICA
}

FORMACIÓN DE MASCULINIDADES: UN ANÁLISIS DE LAS RELACIONES PRESENTES EN UNA ESCUELA PUBLICA

\section{SHAPING OF MASCULINITIES: ANALYSIS OF THE RELATIONSHIPS IN A PUBLIC SCHOOL CLASS}

\author{
Carol Corso von Eye1 \\ Heloisa Junqueira2
}

\section{RESUMO}

No percurso escolar, o ser aluno se dá de forma diferente para meninos e meninas. Ser um bom aluno e se constituir como o menino esperado socialmente, pode ser muito improvável. Buscou-se analisar a formação de masculinidades no cotidiano de uma escola pública, Porto Alegre, RS, e seus efeitos na constituição identitária dos meninos. Considerando o caráter discreto da pedagogia da sexualidade, realizou-se uma pesquisa qualitativa com estudantes de uma turma de nono ano, objetivando contribuir aos estudos sobre formação de masculinidades. Os dados obtidos através de observação participante das relações escolares, e de entrevistas com professoras da turma observada, foram organizados em uma narrativa empírica, discutida e analisada sob pressupostos da análise de conteúdo. Teorizam-se algumas violências constituintes do 'virar homem' na escola e suas implicações na identidade, comportamento e saúde dos meninos.

PALAVRAS-CHAVE: Masculinidades. Escola pública. Identidade. Relações de gênero.

\section{RESUMEN}

1Professora de Ciências Biológicas pela Universidade Federal do Rio Grande do Sul. Especialização em Ecologia Urbana (em realização), UNINTER - Porto Alegre, RS, Brasil.

${ }_{2}$ Doutora em Educação em Ciências, UFRGS; Professora Adjunta da Faculdade de Educação, Universidade Federal do Rio Grande do Sul - Porto Alegre, RS, Brasil. 
En la trayectoria escolar, el ser alumno se hace diferentemente para niños y niñas. Ser un buen alumno y constituirse como el niño esperado socialmente, puede ser muy improbable. Se buscó analizar la formación de masculinidades en el cotidiano de una escuela pública, Porto Alegre, RS, y sus efectos en la constitución identitaria de los niños. Considerándose el carácter discreto de la pedagogía de la sexualidad, fue realizada una investigación cualitativa con estudiantes de una clase del noveno año, objetivando contribuir a los estudios sobre la formación de masculinidades. Los datos obtenidos a través de observación participante de las relaciones escolares, y entrevistas con profesoras de la clase observada, fueron organizados en una narrativa empírica, discutida y analizada con los suportes del análisis de contenido. Se teorizan algunas violencias constituyentes del 'hacerse hombre' en la escuela y sus implicaciones en la identidad, comportamiento y salud de los niños.

PALABRAS-CLAVE: Masculinidades. Escuela Publica. Identidad. Relaciones de género.

\section{ABSTRACT}

In the school trajectory, being a student goes differently for boys and girls. It may be very unlikely.to be a good student and build yourself like the boy you are expected to be. It sought to analyze the shaping of masculinities in the school routine of a public school, Porto Alegre/RS, and its effects in the identitary construction of the boys. Considering the discreet character of the pedagogy of sexuality, it was realized a qualitative investigation, with students of a ninth grade class, aiming to contribute to studies about formation of masculinities. The data obtained through participant observation of school relationships and semi-structured interviews with teachers of the observed class, were organized in an empirical narrative, discussed and analyzed with the notions of content analysis. Some of the violence that constitutes 'becoming a man' at school is theorized, with implications for their identity, behavior and health.

KEYWORDS: Masculinities. Public school. Identity. Gender relations.

$$
* * *
$$

\section{Introdução}

A masculinidade pode ser entendida como "uma configuração de prática em torno da posição dos homens na estrutura das relações de gênero" (CONNELL, 1995, p. 188). Admite-se mais de uma configuração possível, a depender dos contextos históricos e socioculturais. Neste artigo, concebe-se o gênero como sendo mais que um "pout-pourri de identidades e estilos de vida relacionados ao consumo" (CONNELL, 1995, p.188), considerando dinâmicas de poder que delineiam relações inter e intragênero e as variações do padrão normativo na temporalidade histórica (STREY, 2001). A masculinidade hegemônica (CARRIGAN; CONNELL; LEE, 1985) é um modelo normativo entendido como o "padrão de práticas (i.e., coisas feitas, não apenas uma série de expectativas de papéis ou uma identidade), que possibilitou que a dominação dos homens sobre as mulheres continuasse" (CONNELL; MESSERSCHMIDT, 2013, p. 245). 
Formação de masculinidades: análise das relações presentes em uma turma de escola pública

Segundo Escosteguy (2010, p. 47) os Estudos Culturais “questionam a produção de hierarquias sociais e políticas a partir de oposições entre tradição e inovação, entre a grande arte e as culturas populares, ou, então, entre níveis de cultura”. Aprofundamentos teóricos neste campo de estudo, levam à complexificação das identidades culturais tidas como 'outras', ou ainda, outro do outro3. Mulheres, pessoas racializadas e população LGBT4 percebem os reflexos desses marcadores no seu lugar social. Todavia, homens brancos heteronormativos, beneficiados pelo sistema racista e patriarcal, não se observam como sujeitos racializados ou generificados; concebem sua própria experiência no mundo como universal.

Presos a uma formação identitária que lhes violenta, os meninos 'normais' brancos, heterossexuais - foram os menos tocados pelos estudos feministas. Esta violência é diferente da que acomete mulheres, LGBT e pessoas negras: gera identidades que perpetuam um modelo de hierarquia e desigualdade social; nega aos meninos vulnerabilidades, afetividades e os impõe a autovigilância de suas identidades. Conforme Pedro (2005), o estudo das masculinidades é proveniente de impactos da segunda onda do feminismo, entre 1960 e 1980, e uma de suas pautas centrais consistia em evidenciar os privilégios socioculturais da masculinidade, se ocupando pouco com o que transforma meninos em homens, a educação (SILVA, 2015).

Sendo os processos educativos indispensáveis às compreensões sobre formação de masculinidades, aliados à força constitutiva da universalização da identidade de homem branco, apresenta-se neste artigo elementos empírico-teóricos gerados por uma pesquisa qualitativa em uma escola pública estadual, Porto Alegre, RS. Objetivou-se analisar os processos de formação das masculinidades em turma do $9^{\circ}$ ano, Ensino Fundamental (EF). A força analítica deste objeto conduziu aos itinerários da pesquisa5, mediados por observação participante, entrevistas semiestruturadas com professoras e anotações no caderno de campo, com foco nas experiências e relações interpessoais dos estudantes, atravessadas pela pedagogia da sexualidade (LOURO, 2000). A pedagogia da sexualidade, que disciplina corpos, segundo Louro (2000, p. 14) refere-se ao "processo de escolarização do corpo e produção de uma masculinidade" e é "sutil, discreta, contínua, mas, quase sempre, eficiente e duradoura”. Em abril de 2019, ao

3 Ribeiro (2017) revisa a categoria do Outro criada por Beauvoir em seu livro O Segundo Sexo (1949) e o relaciona com o Outro do Outro, categoria criada por Grada Kilomba.

${ }_{4}$ Comunidade de Lésbicas, Gays, Bissexuais, Travestis, Transgêneros (GUNDERLOY, 1989).

${ }_{5} \mathrm{VON}$ EYE, Carol; JUNQUEIRA, Heloisa Meninos que veem, mas não enxergam: masculinidades que se constroem numa escola pública de Porto Alegre. LUME/UFRGS, 2019 
longo de $45 \mathrm{~h}$, foram observados adolescentes de 15 a quase 18 anos, seus modos de resolver conflitos em curto prazo, suas formas de comunicação, de organização social e tensionamento das identidades. Este percurso e os dados obtidos mantiveram coerência com objeto de estudo definido: a formação de masculinidades de meninos escolarizados, fabricada pela pedagogia da sexualidade atual.

O critério condutor da escolha de professoras a serem entrevistadas foi o de atuação em diferentes áreas e práticas pedagógicas, com o intuito de abranger timidamente o espectro de diversidade da práxis docente. Destaca-se que todas as entrevistadas eram mulheres e brancas, ainda que estes não tenham sido critérios de escolha. A opção pela abordagem interacionista justifica-se por "[tomar] por objeto de análise toda a situação e o contexto criado no decorrer da entrevista, não se centrando apenas na dualidade pergunta/resposta" (COMIOTTO; GUIZZO, 2016, p. 126), além de permitir uma interação mais livre com as entrevistadas, evitando o engessamento das respostas.

A investigação foi amparada por princípios epistemológicos e metodológicos das pesquisas qualitativas, os quais se centram no "estudo e análise do mundo empírico em seu ambiente natural" (GODOY, 1995, p. 62), priorizando o contato direto e prolongado com o cenário estudado. Rompe-se assim com a suposta independência entre quem pesquisa e quem é pesquisado, evidenciando as relações costuradas no contexto (MOREIRA, 2011). Neste sentido, a metodologia em pauta foi escolhida por se relacionar mais organicamente com o caráter discreto da pedagogia da sexualidade, que atua pela afirmação ou silenciamento (LOURO, 2000).

Relaciona-se também com a necessidade de se exercer um olhar atento para transformar em singular algo que, à primeira vista, parece ordinário, dissipado no cotidiano (GUIZZO, RIPOLL, 2015). A visão e a atenção diligentes exigem o desafio de identificar "quando e como ele [o objeto, o artefato, a prática] se torna suficientemente visível para ser objeto concreto de análise" (WILLIS, 1997, p. 111). Mediados por processos de observação, diálogos e escuta ativa que objetos, relações e práticas invisibilizadas podem se tornar visíveis, excluindo-se assim a busca por uma verdade universal, optando-se por uma metodologia plural de investigação (SANTOS, 1988).

No processamento dos dados coletados, foram escolhidos os contributos da análise de conteúdo (BARDIN, 2011), pois são formados por um conjunto de instrumentos metodológicos em constante aperfeiçoamento, podendo ser aplicado a 
Formação de masculinidades: análise das relações presentes em uma turma de escola pública

discursos extremamente diversificados (BARDIN, 2011). Cenários, contextos, relações sociais e significados diversos são interpretados e analisados em um nível da realidade que não pode ser quantificado (MINAYO, 2002), uma vez que a busca é compreender os universos dos sujeitos em seus cotidianos. Com estes referentes, iniciou-se a organização dos dados, criando agrupamentos em que palavras, teor e sentidos fossem similares, gerando as categorias: autoestima, relações afetivas, condutas e outras. A partir destas, foram criados outros agrupamentos com significados explícitos e não explícitos, o que conduziu ao processo de definição das seguintes categorias de análise: conflito da masculinidade com ser estudante; masculinidades e relações escolares; e autoritarismos escolares. Assim, estabeleceram-se relações entre o observado, as entrevistas e a hipótese de pesquisa com as condutas dos estudantes em sala, e outras nuances percebidas.

\section{Escola fabricando diferenças}

As sociedades são permeadas por múltiplas concepções, que originam antagonismos sociais e forjam uma variedade de identidades e posições de sujeitos (HALL, 2006). Essas identidades transformam-se em pontos de ancoragem às várias formas de preconceito. Na escola como em qualquer espaço de interação social, instituímos marcadores e somos marcados/as com os mais diversos símbolos provenientes da nossa performance social. É comum observar esses marcadores em ação, mesmo através do corpo docente, quando estudantes são chamados de: gordo/a, viado, pretinha, meninos, meninas. Sendo a linguagem um meio de construção dos referenciais do sujeito, ela cria realidades, produz sentidos e valores, resultando em circunscrições identitárias. As palavras demarcam e nomeiam os indivíduos, definindo o que poderá acontecer com eles (SILVA, 1994).

Por ser um espaço de vivências cotidianas específicas e plurais, é possível atribuir à escola parte da responsabilidade pelo processo formativo das identidades sociais (MEYER; SOARES, 2004). Ela não cria a matriz geradora da desigualdade social, mas ao reproduzi-la, produz comportamentos que a perpetuam. Baseando-se nas competências profissionais atribuídas a professores/as, a escola modela os sujeitos ao formá-los para além dos currículos em ação, forjando comportamentos e moralidades, buscando enquadrá-los em um padrão de normalidade social (ÁLVAREZ URÍA, VARELA, 2009). A instituição escolar continua expressando poderes masculinos, hierarquias e valores normatizados, retificadora de quem se distancia da norma. 
Narrativas escolares produzem noções sobre quais comportamentos são desejáveis ou não, dependendo do gênero designado. Assim, o que é dito ou não na escola passa a ser elemento constituinte das identidades de crianças e jovens. Como Meyer, Klein e Andrade (2007) apontam, as práticas escolares e culturais centralizam certas identidades e comportamentos como sendo as 'desejáveis' ou 'normais', criandose fronteiras que afastam sujeitos, porém formam grupos. A naturalização de comportamentos ditos masculinos ou femininos se materializa em desigualdades e hierarquias, que transmitem a sensação de permanência e imutabilidade nos contextos sociais (STREY, 2015), alijando discussões sobre desigualdades construídas ao redor das diversidades de gênero, de raça e de sexualidade.

É preciso nomear as realidades sociais para alterá-las. Portanto, "temos de estar atentos/as, sobretudo, para nossa linguagem, procurando perceber o sexismo, o racismo e o etnocentrismo que frequentemente carrega e institui" (LOURO, 1997, p. 64). Um exemplo refere-se às palavras historicamente enunciadas que seguem construindo a crença de que mulheres são mais organizadas, dedicadas e cooperativas "por natureza", e homens têm "naturalmente" maior potencial cognitivo. Pode-se afirmar assim que a escola perpetua a produção de comportamentos que reforçam as desigualdades de gênero.

Ainda que no contexto do marcador social gênero os meninos ocupem a posição de norma, não se pode dizer que não há conflito identitário. É preciso compreender as diferentes formas de ser menino, e as relações que se forjam entre diferentes tipos de masculinidades. Estas masculinidades são construídas através de práticas comuns na escola: exclusão, intimidação, inclusão, etc. Há uma política de gênero intrínseca à masculinidade (CONNELL; MESSERSCHMIDT, 2013). Com Seffner e Da Silva (2016, p. 397), ilustra-se a complexidade dos atravessamentos de gênero na experiência escolar: "tornar-se aluno se dá de maneira diferente para meninos e meninas; é fortemente influenciado pelo marcador gênero".

A ameaça à produção das masculinidades cria um conflito: talvez seja impossível ser bom aluno e construir-se como o menino esperado. De acordo com Seffner e Da Silva (2014, p. 48), “o esforço em seguir critérios que asseguram aos meninos seu ingresso no mundo dos homens entra em conflito com os modos pelos quais a escola define o que é ser bom aluno". Os meninos experienciam uma fragmentação: entre as expectativas do projeto de masculinidade e sua dedicação à 
trajetória escolar. Para se sentirem seguros e parte de um grupo respeitado, os meninos podem renunciar dos estudos.

\section{"Elas vão melhor"}

Apesar das mulheres brasileiras terem adentrado o século $\mathrm{XX}$ quase em sua totalidade não alfabetizadas (MEYER; KLEIN; ANDRADE, 2007), dados do Inep (2009)6 mostram que hoje elas cursam mais anos escolares e acessam mais o ensino superior do que os homens. Contudo, segundo o IBGE (2003) há mais homens exercendo cargos políticos, no serviço público e no comando de empresas. Ao analisar índices brasileiros7 de defasagem entre idade-série, Carvalho (2003, p.186) observou que meninos de até 16 anos tendem a ficar $10 \%$ mais atrasados na sua escolarização do que as meninas. Afirma que "a diferença entre as proporções de homens e mulheres alfabetizadas tem a ver com o percurso escolar que meninos e meninas fazem no nosso ensino, evidenciando uma trajetória mais longa e mais tumultuada para as pessoas do sexo masculino".

Conforme Silva et al. (1999), os alunos conformam-se às expectativas das professoras, submetendo-se. Expressam que estudantes tidos como bem sucedidos, não são foco de pesquisas, pois não configuram um 'problema' e, muitas vezes, renunciam aos próprios referenciais de comportamento para atender a expectativa a eles projetada, vivendo um conflito entre seus valores e os da escola. Estudantes que se submetem assumem comportamentos passivos - características socialmente tidas como femininas. A suposição de que meninas têm mais sucesso escolar em decorrência deste comportamento submisso é também justificada através do papel por elas desempenhado na organização familiar, e da socialização primária que recebem. Nessa lógica, o sucesso escolar das meninas provém de seu bom comportamento e não de sua capacidade cognitiva.

Entretanto, a hipótese de que os meninos falham no desempenho escolar por não serem socializados com características definidas como femininas não é suficiente para explicar sua majoritária reprovação, já que o vigente modelo de ensino valoriza alunos contestadores, participativos e com condições de liderança - características associadas a homens. Apesar dos dados indicarem maior taxa de reprovação nos meninos, Carvalho

6 Instituto Nacional de Estudos e Pesquisa (2009) - Mulheres estão em maior número na educação superior.

7 Dados do Instituto Brasileiro de Geografia e Estatística (IBGE), 1996. 
(2003, 2004) expressa que professoras tendem a caracterizar o seu desempenho escolar como excelente; as meninas são rotuladas como medianas, boas alunas, não tão brilhantes, e os meninos 'problemáticos' como alunos ruins.

As entrevistas foram realizadas em 2019, junho, período em que se mantinha o parcelamento de salários das professoras por arbítrio da Secretaria Estadual de Educação. Na pequena escola há um ar de familiaridade entre boa parte dos estudantes, professoras e servidoras. Quando as professoras estavam disponíveis, se direcionavam a Biblioteca para as entrevistas, sendo a professora Carmens de Português a primeira entrevistada, que demonstrou grande afeto e empatia com a realidade social de seus alunos. Com Helena, professora de História, deu-se a segunda entrevista, aparecendo sua relação conflituosa com a turma, envolvendo discussões e xingamentos. A terceira entrevista foi com Raquel, professora de Ciências, que revelou sentir muito carinho por seus alunos, contudo se reconhece e é reconhecida por sua exigência. No roteiro das entrevistas semiestruturadas, elaborado após o período de observação, incluiu-se temáticas que pudessem gerar compreensões mais profundas dos/das sujeitos de pesquisa, como percepções das professoras sobre relações de gênero, masculinidades, conflitos interpessoais, relações de afeto/desafeto entre estudantes e professoras, além da temática do corpo e seu aparecimento nas aulas.

Durante o período de observação, as meninas exibiam mais aplicação nas tarefas escolares. Tão logo a professora propunha uma atividade, iniciavam sua execução, dividiam tarefas e discutiam ideias. A maioria das meninas entregava seus trabalhos sem atrasos e suas apresentações tinham melhor desempenho. Foi consenso entre as entrevistadas que os trabalhos das meninas, apesar de não muito bons, eram melhores que o dos meninos. Perguntei a Carmen se ela achava que "as meninas tiram notas melhores que os meninos?" e ela diz:

[Carmen] Com certeza as médias delas vão ser bem melhores. Apresentação do trabalho delas foi melhor, o visual do trabalho delas foi melhor, e eu acredito que para prova semana que vem elas vão melhor.

A estas diferenças de desempenho, variadas justificativas aparecem: mais maturidade das meninas, a importância que dão à escolarização, a capacidade de organizar-se. Na fala das professoras, fica evidente a noção de maturidade como

${ }_{8}$ Neste texto, todos os nomes são fictícios. 
Formação de masculinidades: análise das relações presentes em uma turma de escola pública

condutora dos sucessos escolares das meninas. Concordam que as meninas são mais maduras que os meninos desta turma. Exemplificando:

[Carmen] É uma questão assim de maturidade dos meninos e das meninas. Porque a gente vê isso, da menina ser mais caprichosa, ser mais interessada em fazer, é quase em todas as turmas. As meninas são mais dedicadas a fazer apresentação do trabalho, é sempre melhor.

[Raquel] As meninas já têm também uma outra postura. A gente tem meninas aqui que são casadas ou já foram casadas, ou pelo menos já tiveram relações assim, de longo tempo. Elas têm essas vivências. Os meninos que eu saiba nenhum deles tem essa vivência ainda.

[Raquel] Infelizmente nós ainda temos isso na sociedade né, que não cobra isso deles, mas cobra isso delas né. É bem complicado, tu vai ver se tu conversar com elas, todas elas têm responsabilidades em casa, têm responsabilidade com os irmãos. Elas têm responsabilidades, eles não tem. Um menino, o homem ele não tem essa responsabilidade. De fazer as tarefas, de ajudar em casa né. E elas têm, elas são cobradas por isso.

Parte das entrevistadas reconhece um ponto de origem para maturidade das meninas: a socialização como mulher e os papéis que desempenham em suas famílias. Helena concorda com a relação do melhor desempenho e maturidade das meninas, mas discorda que a maturidade advenha de pressão social:

[Helena] Eu acho que as gurias que estão ali não têm responsabilidade nenhuma. É mais assim uma questão acho que se afirmar, de querer mandar, essas bobices. Mesmo assim a menina é mais madura entendeu, então elas acabam deixando eles muitas vezes de lado.

O espaço escolar é pedagógico e é onde "operam representações engendradas em relações de poder que incitam indivíduos a ser e viver de determinada maneira e não de outras, a pensar e sentir determinadas coisas e não outras" (MEYER; SOARES, 2004, p. 16). É preciso, cada vez mais, reformular posicionamentos biologicamente deterministas, que limitam as possibilidades de ser menino ou menina. Entre os meninos, também há discussões acerca do conceito de maturidade. De que precisam abrir mão para se tornarem maduros? Um diálogo testemunhado entre dois meninos mostra o que pensam sobre maturidade. Um aluno (A) fazia um avião de papel com a cartolina que sobrara do trabalho. Um colega (B) o confrontou. Diálogo entre eles:

\footnotetext{
B: Quantos anos tu tem?!

A: Quinze, mas eu sou feliz!

B: Nada, tu é infantil!
} 


\section{A: Pelo menos eu não fico aí serião.}

A maturidade representa um componente da construção de masculinidades. Segundo Felipe (2000) os devaneios, os sonhos, as fantasias trazem perigo para a construção de um projeto de homem, em específico aos das classes populares. Os referenciais de masculinidade, pouco presentes na escola, tornam-se os homens de sua convivência, inclusive seus colegas. Ao mesmo tempo em que a maturidade os limita a serem menos criativos, inventivos e livres, a falta dela os coloca em um lugar de aprendizagem e desempenho escolar inferior ao das meninas. $\mathrm{O}$ segundo argumento que justifica a diferença de desempenho, baseia-se na visão de que as meninas estão mais cientes da necessidade da escolarização - é através dela que tentarão se movimentar a fim de alterar seu lugar na hierarquia social. A professora Raquel afirma:

[Raquel] Sempre se dedicam mais, e volta toda aquela coisa dessa construção de gênero que a gente tem que a menina tem que ser mais dedicada né, mais organizada, que ela tem que ser melhor né, então elas já trazem a construção.

Carmen expressa um entendimento semelhante ao da Raquel, de que as meninas sabem que precisam da escola para alterar suas realidades:

[Carmen] Elas têm mais maturidade de pensar que elas precisam disso. Elas não vão chegar a lugar nenhum se elas não estudarem. Se elas não forem atrás. Os meninos parece que tão a passeio aqui na escola.

Quando questionada sobre os meninos e seus projetos de futuro, Raquel disse: "Parece que não são cobrados em relação a isso, mas elas são", alinhando-se a algumas teorizações. Uma delas propõe que os meninos não sentem necessidade de empenhar-se por compreenderem que as melhores oportunidades ficam reservadas a eles, em virtude da predominância masculina na configuração social.

A partir desse cenário, é sensato pensar que, ao longo de sua vida, um menino percebe e identifica que seu lugar social está garantido (SEFFNER; DA SILVA, 2016). Porém, essa constatação não considera outros fatores como raça e classe social. A maioria dos homens que obtêm sucesso é branca, e poucos de origem da classe trabalhadora. Talvez por serem educados como sujeitos universais 9 , os meninos brancos não percebem que são atravessados por diversos marcadores. Efeitos desse não-esforço escolar poderão incidir em seus percursos futuros. Portanto, pode ser que para os

9 Ribeiro (2017), instiga a pensar quais realidades são consideradas implícitas na normatização hegemônica e quais são "alternativas". Refuta visões universais de mulheridade e negritude, propondo que homens brancos, que se pensam universais, se racializem e compreendam o que ser branco significa. 
Formação de masculinidades: análise das relações presentes em uma turma de escola pública

meninos o esforço escolar seja desnecessário, já que no futuro, as meninas acabam sendo subalternas a eles (SEFFNER; DA SILVA, 2014). Com essa mentalidade a escola os "nivela por baixo", aceitando desempenhos medíocres como suficientes. É necessário ensinar aos meninos a se verem como pessoas atravessadas por alguns privilégios, mas prejudicadas por uma estrutura social da qual não são os maiores beneficiários.

Outra argumentação da diferença nos desempenhos entre meninas e meninos indica uma melhor adaptação das meninas à estrutura escolar, pois sua socialização implicaria em boa capacidade comunicativa e cooperativa. Observando as aulas, os grupos de trabalho se dividiam por gênero, exceto pelo aluno gay, que realizava o trabalho com as meninas. Elas, quando faziam um trabalho coletivo, separavam as tarefas e recebiam elogios das professoras. Os meninos demoravam para se organizar em grupos e começar o trabalho. Uma vez que estavam juntos, não dividiam as tarefas e mais de uma vez se observou um deles fazer o que era pedido de todo o grupo.

Ao observar as interações entre meninos e meninas nas aulas, ficou evidente que vivem a escola de forma diferente. Quando faziam trabalhos em dupla compostos por um menino e uma menina, na maioria das vezes o trabalho era executado e organizado pela menina, ficando o menino como auxiliar e fazendo apenas o que lhe fosse pedido. Quando um dos meninos reclamou de realizar um trabalho atrasado no final de semana, as meninas riem dele e dizem: "Se tivesse feito quando era pra fazer, não precisava fazer no finde10, e é rápido!" [aluna], indicando que era um trabalho simples de ser feito - pelo menos para ela.

A partir das observações, identificou-se um elemento auxiliar nas meninas para seus desempenhos em trabalhos em pequenos grupos: costumam fazer esforço comunicativo e estabelecer consensos em seus grupos, facilitando a distribuição das tarefas e realizando o que se pede. Foi perguntado à Carmen sua posição frente a diferença de performance entre meninas e meninos, em atividades de pequenos grupos, ela disse:

[Carmen] As meninas trabalham melhor porque todas trabalham [...]. Eu acho que elas cobram também umas das outras mais assim, tu tem que fazer isso, elas sabem dividir melhor, elas organizam melhor a coisa assim.

${ }_{10}$ Final de semana. 


\section{"As esforçadas e os preguiçosos"}

As professoras e a escola, conscientes ou não, avaliam meninos e meninas de formas diferentes. Partindo do pressuposto de que as meninas são 'mais adaptadas' à lógica escolar, entende-se que os meninos estão em desvantagem por sua socialização. Em virtude deste entendimento, os padrões esperados das meninas são mais elevados que o dos meninos. O uso repetido da palavra 'conseguir' atrelado aos esforços de desempenho deles ilustra a visão que as professoras têm dos meninos: limitados em seu desenvolvimento e incapazes de construir sua própria jornada escolar de forma mais positiva. Sobre o desempenho dos meninos, pergunta-se se os meninos reprovam mais por não conseguirem aprender ou outros motivos. Sobre provas, Helena diz:

[Helena] Eles não conseguem fazer. Eles não conseguem fazer, eles tão com caderno na frente, eles não conseguem se concentrar.

Sobre a participação em aula, relata dificuldade deles:

[Helena] Falar, de participar mais ativamente, não conseguem. Eles não conseguem ver o que eles estão vendo e interpretar.

Segundo Silva et al. (1999, p. 215), as formas de explicar essas diferenças no desempenho escolar expressam a noção de que "os meninos são mais inteligentes, porém, indisciplinados; enquanto as meninas são atentas e aplicadas, mas menos inteligentes". Essas representações presentes nas falas das entrevistadas contribui para formar as concepções de bom aluno. $\mathrm{O}$ efeito que essas compreensões poderão gerar vincula-se ao próprio comportamentos dos alunos. As impressões das docentes reforçam o modelo de comportamento esperado dos meninos e meninas na escola e na sociedade.

Para a pergunta "Você vê alguma diferença entre as meninas e os meninos?" Carmen comenta:

[Carmen] As meninas são bem mais responsáveis, elas fazem as coisas, elas se interessam. Elas trazem material, elas vão atrás; e os meninos, infelizmente os nossos, são muito preguiçosos.

A contraposição feita à responsabilidade das meninas é a preguiça dos meninos, não a irresponsabilidade - retirando deles o compromisso com sua escolarização. É perceptível que as vitórias delas e o fracasso deles são medidos por réguas diferentes. Os meninos são mais indisciplinados, mais desorganizados e as meninas têm um comportamento que facilita o "ser aluno". As meninas já viriam de sua família e socialização primária mais preparadas para exercer esse ofício, porque seriam mais 
Formação de masculinidades: análise das relações presentes em uma turma de escola pública

passivas, obedientes, calmas, silenciosas, caprichosas (SILVA et al., 1999). Já os meninos seriam inteligentes, mas avessos ao esforço. Para o sucesso escolar só faltaria vontade. Para as meninas, seria necessário esforço para serem boas ou medianas, o que pode indicar a força da relação entre pensamento lógico-matemático, inteligência e masculinidade, exemplificado nas falas:

[Helena] Ele é muito inteligente, só que não se esforça.

[Raquel] As meninas se dedicam mais.

[Raquel] Em física - que é mais matemática mesmo - as meninas, elas se dedicam muito mais, têm melhores resultados que os meninos né, porque elas se dedicam muito mais.

[Raquel] Então normalmente tu pega um trabalho de uma menina e um menino daqui mesmo, o da menina vem todo organizado, com capa, com tudo. Ela se dedica mais a fazer. Se é dela ou se é de uma construção que já vem, eu acredito que é de uma construção que já vem, ela tem que ser boa.

Nas aulas em que os/as estudantes realizavam atividades individuais e chamavam a professora para tirar dúvidas, as meninas eram menos ouvidas e menos atendidas. Suas vozes eram mais baixas e mais discretas: chamavam a professora e aguardavam sentadas. Já os meninos elevavam o tom de voz, repetiam o chamado e, quando não atendidos no ato, deslocavam-se até ela - mesmo que estivesse atendendo outra pessoa. Corroborando a reflexão de Thorne (1993 apud CONNELL; PEARSE, 2015, p. 56), de que os meninos fazem mais "movimentos agressivos e reivindicam poder", observou-se que estes interrompem mais as meninas do que o oposto. Essa observação possibilita questionar o quão adaptativos são os atributos 'silenciosas, calmas, ordeiras, passivas' para as meninas em uma trajetória escolar que, muitas vezes, requer um papel mais ativo.

Essas condutas ilustram meninos que não costumam aguardar, que são impulsivos com suas palavras e corpos. Uma masculinidade impaciente não aceita nada aquém do que demanda, espelhando os homens adultos de hoje, fundamentados em uma masculinidade exigente e desatenta ao seu redor. Quando as professoras alimentam esse modelo de atendimento aos meninos, acabam por validar estas práticas de intervenção e o silenciamento das meninas. Este atendimento preferencial aos meninos tem implicado nos insucessos escolares. Ao preterirem as meninas, as professoras favorecem a sua independência e, ao preferirem os meninos, promovem uma formação de sujeitos dependentes, que exercitam pouco a comunicação, organização em grupo e paciência. 


\section{Que meninos a escola forma?}

Em um complexo habitacional do bairro em que a escola se situa, e muitos dos estudantes residem, há um ponto de tráfico. Neste espaço, há tensionamentos relacionados à polícia e venda de drogas. Essa realidade afeta alunos brancos e negros de formas diferentes. Em relação aos alunos brancos, Carmen diz que, as mães dos meninos que lá moram, a fim de evitar o envolvimento deles com esse mundo, não permitem sua socialização nas redondezas de casa. Por este fato, a escola torna-se o lugar estável para criar laços e amizades, proporcionando que estes meninos mantenham traços de comportamentos infantis - improváveis de acontecer fora dela. Esses meninos 'brincalhões' aparentam não se preocupar com seu desempenho, e talvez por isso sejam respeitados por seus colegas. Resistir às normas escolares pode ser um modo de se constituir menino e obter aceitação e autoestima (SEFFNER; DA SILVA, 2016). Observa-se nas falas das professoras uma naturalização da resistência masculina em participar das aulas.

Resistindo ao processo de escolarização, esses meninos constroem masculinidades de protesto (CONNELL; MESSERSCHMIDT; 2013). Nesse cenário, a autoridade escolar se constitui como antagonista principal, e será pelo enfrentamento neste contexto que o sujeito afirmará sua identidade. Ademais, a masculinidade de protesto pode ser entendida como um padrão de condutas construído num contexto de classe trabalhadora - por vezes entre grupos marginalizados por questões raciais - que incorpora a reivindicação de poder típica das masculinidades hegemônicas nos países ocidentais (CONNELL; MESSERSCHMIDT, 2013). Atentar à forma como se constrói essa masculinidade de protesto permite compreendê-la e evitar cair no discurso biologizante dos comportamentos masculinos. Eles não se engajam nessas práticas de resistência por hormônios de agressividade, mas para conquistar destaque e valoração entre seus colegas. É por meio da resistência aos processos de escolarização que suas identidades se desenvolvem gradativamente, porque obter prestígio pelo sucesso escolar é improvável nesse contexto socioeconômico.

A vivência próxima ao tráfico de drogas não cria somente meninos que desejam continuar infantis, mas também os que são influenciados pela vida oferecida por ele. Dois alunos negros, Rafael e Bruno, apresentam performance de identidade mais próxima desse mundo e a escola reforça que sigam por esse caminho. Quando os meninos falam palavrão, e uma das colegas diz que "É coisa de vila" [aluna], a professora de Geografia responde: “É, mas podem deixar a vila pra fora da escola”. As 
Formação de masculinidades: análise das relações presentes em uma turma de escola pública

professoras naturalizam comportamentos sociais como inerentes a eles e selam seu destino: "Parece que tem prazo de validade" [Carmen]. O status obtido por eles frente a seus colegas não vem do envolvimento direto com as drogas, mas de uma relação existente com esse mundo, como uma forma de resistência às normas e valores da escola, família e sociedade, articuladas com a construção de suas masculinidades (SEFFNER; DA SILVA, 2016).

Se a pedagogia da sexualidade advém dos valores e princípios socialmente estabelecidos, é coerente dizer que um de seus componentes seja o racismo. De acordo com Carneiro (2005, p. 324), a escola "tem se constituído, de forma quase absoluta, para os racialmente inferiorizados, como fonte de múltiplos processos de aniquilamento da capacidade cognitiva e da confiança intelectual”. A negação à condição de sujeito de conhecimento aos estudantes negros/as se dá por rebaixamento da autoestima, discriminação e imposição do embranquecimento cultural, produzindo fracasso e evasão escolar (CARNEIRO, 2005). Em um dos meninos citados por Carmen, Rafael, foi possível identificar uma performance de masculinidade hegemônica e a tentativa de obter vantagens, poder, através da dinâmica de gênero escolar. Rafael, com mais idade do que a maioria dos colegas - com mais reprovações também -, se mantém em silêncio na maior parte da aula e não realiza nenhuma tarefa; apesar disso, seus colegas colocam seu nome nos trabalhos. Rejeita a escolarização de forma discreta, e reforça sua posição ao debochar de seus colegas que se dedicam às atividades.

A masculinidade hegemônica se reforça e se perpetua ao diferenciar-se de outras masculinidades, mediante alianças, dominação ou subordinação. Essas relações se constroem através de práticas que incluem, excluem, intimidam ou exploram as identidades não-hegemônicas (CONNELL; MESSERSCHMIDT, 2013), permitindo visibilizar uma hierarquia dentre os homens. Essas estruturas existem em diversos cenários e a versão hegemônica varia de acordo com o contexto local. $\mathrm{O}$ menino que expressa essa masculinidade hegemônica é apoiado por seus colegas - masculinidade cúmplice, que se alia para intimidar ou excluir meninos com condutas menos masculinas, como o menino gay.

Carmen compartilha que percebe essa ridicularização dos meninos mais dedicados aos estudos:

[Carmen] Até às vezes quando um menino faz uma coisa muito bonitinha, enfeitadinha, os outros já ficam debochando. Eles têm 
ainda essas bobagens na cabeça deles, de menino não pode usar uma caneta rosa no caderno, por exemplo. É ridículo mas eles ainda têm.

Neste contexto, esforço e bom desempenho escolar contrariam a identidade almejada: há um conflito entre os projetos de masculinidade e escolarização, que gera medo e ansiedade sobre sexualidade e condição de menino, resultando em indisciplina, agressividade e até evasão escolar. Não há a possibilidade de um menino ter bom desempenho e ser respeitado por isso - portanto, preconiza o projeto de masculinidade, atravessado pela raça, em detrimento da trajetória escolar.

\section{“Os guris é muito filhinho da mãe, e tá certo"}

As professoras também estão sujeitas aos processos de formação identitária e lidam com as expectativas da sociedade sobre seu trabalho pedagógico, vivendo diversas pressões na escola. Muitas vezes, sobrecarregadas, atuam instintiva e empiricamente. Nesses momentos fugazes, é possível identificar comportamentos e atitudes internalizadas, que favorecem os meninos na sala de aula, mas também podem prejudicá-los no futuro. Carmen, comenta sobre as meninas com mais idade da turma e faz um contraponto: "Os guris, é muito filhinho assim da mãe e tá certo a idade deles é isso mesmo e elas não são”. Comenta que essas meninas já poderiam ter finalizado o Ensino Médio, pois "já são moças" [Carmen]. A fala indica uma dicotomia de tratamento entre os alunos que diferem de pouco em idade. A professora infantiliza os meninos e torna as meninas quase adultas, no critério responsabilidade.

Outra sutileza observada foi a tendência das professoras a proteger os meninos de decepções e frustrações. Para compreender sua ação, é preciso saber que há uma separação presente na turma, posterior às eleições presidenciais de 2018, os meninos se puseram a favor do candidato Bolsonaro, as meninas e o menino gay se posicionaram contrários. Observou-se, durante uma apresentação sobre feminicídio, esforço da professora para evitar que os meninos se sentissem contrariados. As meninas que apresentavam quiseram criticar o governo Bolsonaro por suas políticas públicas contra a saúde e segurança da mulher. Quando mencionaram seu nome, a professora cortou a fala delas e pediu que não falassem sobre isto para evitar incômodos, direcionando um olhar de preocupação aos meninos, que não haviam esboçado nenhum tipo de resposta. Na tentativa de evitar atritos, a docente impede uma discussão em que se poderia trocar opiniões e aprendizados - pelo temor de um possível desconforto dos meninos, ignora e silencia os desconfortos das meninas. 
Formação de masculinidades: análise das relações presentes em uma turma de escola pública

Noutra situação, uma das professoras discorre sobre o conselho dado a um aluno negro quando ele lhe confessou sentimentos por uma colega. Por não ver possibilidade da relação, ela lhe diz:

[Carmen] Tenta olhar para outra porque a Ana cada hora é um que ela tá.

Desabafa que não quis dizer ao aluno que a menina não teria interesse, porque "Ele é negro e ela é nojentinha pra essas coisas" [Carmen]. Ao invés de falar sobre o racismo em questão, desvia dizendo que não a achava tão bonita: "Já esculhambei a guria pra ele” [Carmen]. A professora evita tratar do racismo na predileção dos afetos da aluna e opta por atacar a conduta dela. Essa forma de atuação, impede que o menino se instrumentalize contra o racismo que encontrará na vida, responsabiliza a mulher pela impossibilidade da relação, não apresentando o real motivo do desinteresse da menina e fortalecendo um estigma sobre os comportamentos afetivo-sexuais dela.

Cabe lembrar que os cuidados dados às crianças no paradigma cultural vigente são feitos, em sua maioria, pela mãe, o que influencia a construção dos sujeitos e repercute em seus processos de aprendizagem (SILVA et al., 1999). O magistério ainda é visto como uma extensão da maternagem (ROSEMBERG, 1992 apud SILVA et al., 1999) criando uma relação complexa e que confunde a atividade profissional de educar crianças com a doméstica/afetiva. Pode ser um ponto de reflexão para compreender as relações entre a afetividade das professoras e a reprovação dos meninos. Carmen demonstra preocupação:

[Carmen] Os meninos ali, eu acho que eles vão reprovar. Não vão reprovar só comigo, eles vão ficar. Eu tô preocupada com eles, porque eu não vejo preocupação.

As entrevistadas não tinham dados indicando que os meninos desta turma tivessem mais reprovações do que as meninas, tampouco informações suficientes sobre os desempenhos no ano letivo para afirmar o que disseram, à época. Contudo, conseguem antecipar que eles serão os mais reprovados. Com isto, é possível identificar a "profecia autorrealizadora", enunciando "quando professoras esperam que certos alunos mostrem desempenho intelectual maior, estes alunos mostram de fato um melhor desempenho" (ROSENTHAL; JACOBSON, 1968, p. 20)11. Essas expectativas das

${ }_{11}$ Tradução minha do texto original em inglês de Rosenthal e Jacobson, Pygmalion in the classroom (1968). 
professoras, sejam negativas ou positivas, são explicitadas aos estudantes por meio da expressão de emoções, ações de apoio ou rechaço a determinadas práticas e falas - o que pode afetar o desempenho dos estudantes. É necessário pensar o efeito dos estereótipos de gênero e raça na definição das trajetórias escolares, levando em consideração que os marcadores menino/menina precedem a própria escola e constituem as percepções empíricas das professoras (SILVA et al., 1999).

\section{Vale-tudo: conexões através da violência}

O contato físico entre os meninos tende a ocorrer por provocações e violência, formas de interações consideradas seguras neste ambiente de observação e controle da sexualidade. As brincadeiras mais comuns são desferir socos, chutes leves, petelecos e qualquer forma agressiva de contato físico. Os meninos parecem tentar chamar atenção dos outros de forma indireta, quase despretensiosa: escondendo os materiais dos colegas, jogando bolinhas de papel, fazendo piadas depreciativas. A participação da maioria nessa troca de gestos e falas agressivas sugere uma "cumplicidade com um ideal de masculinidade hegemônica orientada ao poder" (JEWKES; MORRELL, 2012 apud CONNELL; PEARSE, 2015, p. 116).

Das piadas que fazem, todas caem no espectro do humor depreciativo - muitas vezes autodepreciativo. Como exemplo, observou-se o xingamento gordofóbico de um colega a outro: "Ele não vale a gordura que come". Em momentos de conflito, são esses os marcadores que vêm à tona. E apesar de aparentarem chateados com essas atitudes, os meninos não verbalizam sua insatisfação. Aguardam silenciosos um momento onde possam caçoar do colega que os humilhou. Não foram observados, após xingamentos entre os meninos, pedidos de desculpas e nem momentos de arrependimento. A cada agressão se agrava a necessidade de resistir com frieza.

Segundo Connell e Pearse (2015, p. 116), “com frequência, a violência pública envolve desafios à masculinidade e demonstração de coragem e de domínio masculino", então, como sujeitos em formação, meninos julgam necessário não se dar por vencidos, e nem se deixar afetar. As autoras expressam, ainda, que "as práticas corporais dos homens também obedecem a definições prevalentes sobre ser homem e masculinidade, como aceitação do risco" (2015, p. 116). No ambiente escolar, os riscos podem ser lesão corporal, expulsão da sala de aula ou reprovação. Bourdieu (2012, p. 64) expõe o privilégio masculino como uma cilada que "encontra sua contrapartida na tensão e 
Formação de masculinidades: análise das relações presentes em uma turma de escola pública

contensão permanentes, levadas por vezes ao absurdo, que impõe a todo o homem o dever de afirmar, em toda e qualquer circunstância, sua virilidade”.

Analisando esses tensionamentos, precisa-se atentar aos preconceitos e construções subjacentes ao que achavam engraçado. Identificar as divergências entre as professoras sobre a noção dos estudantes serem ou não preconceituosas foi muito significativo. Ao ser perguntada se achava que os meninos eram preconceituosos, Carmen diz:

[Carmen] Eu acho que não, mas alguma brincadeirinha em relação ao [aluno gay]. Não convidam nunca ele para coisas, para fazer um trabalho. Na cabeça deles eu acho que não passa a ideia de que ele vá fazer parte do grupo deles.

Excluir o aluno gay do grupo dos meninos não teria a ver com o preconceito, mas com questões de gosto: "Porque ele gosta de outros tipos de atividades, de conversas né" [Carmen]. Ao não reconhecer a homofobia no comportamento dos meninos da turma, a professora endossa o reforço da heteronormatividade na escola, assegurando que estes aprendizes corporificados se adequem ao regime de gênero dessa instituição à qual estão subjugados (CONNELL; PEARSE, 2015). Ademais, o menino gay é obrigado a renunciar seu gênero para construir sua identidade embasada exclusivamente na sexualidade, sendo limitado também por esse marcador na instituição, e pelos colegas. De acordo com Louro (1998) a representação da sexualidade se articula com o gênero masculino de uma forma muito mais central do que com o gênero feminino. De tal forma que, "para os homens modernos, a masculinidade se expressa, pelo menos em parte, através de sua sexualidade" (WEEKS, 1993 apud LOURO, 1998, p. 44). Para viver a homossexualidade, é negado ao menino gay o acesso à sua masculinidade, seu gênero e os privilégios atrelados.

Apesar de não achar os alunos preconceituosos, a professora Carmen, diz já ter presenciado episódios de racismo:

[Carmen] Às vezes têm. Eles fizeram uma piada, 'ah tá mas ele gosta'. Eu chamei atenção e ele disse 'ah mas ele aceita, a gente sempre chamou ele assim'. Eu disse 'pô [aluno alvo de racismo], como é que tá aceitando', e ele respondeu 'mas eles sempre me chamaram'. Ele não reage.

Cobra um posicionamento do aluno negro, alvo do racismo, e não se atenta a quem o produz na sala de aula. Não vê os meninos brancos como preconceituosos e, por 
não reconhecer a presença desses marcadores, não pode agir a respeito. Já a professora Helena, comenta sobre preconceito nas atitudes das meninas:

[Helena] Nunca, pelo contrário. Vejo até em defesa dos animais da floresta; em defesa do mendigo da rua, sabe aquelas coisas assim? Elas defendem todas as áreas. Tudo, entendeu?

A professora Raquel expressa em sua opinião que os estudantes são preconceituosos, e vê “construções em relação a várias coisas, em relação à raça/cor, em relação à questão de ser gordo, em relação a ser bonito, ser feio". Ela partilha da preocupação de terem poucos espaços para discutir essas questões entre si e com colegas. As professoras buscam identificar momentos para intervenções possíveis. Raquel completa: "São poucos os espaços que a gente tem pra essas intervenções”.

\section{Amigos, amigos. Intimidade à parte}

Apesar de estabelecerem relações de amizade, os meninos não parecem ter muita intimidade entre si. Ao ser indagada sobre a capacidade dos meninos estabelecerem relações saudáveis entre si, Raquel afirma:

[Raquel] Eles não têm grupo, daí eles vão meio que no rolão. Eles não se ajudam muito, a gente tem meninos aqui com bastante dificuldade e eles nem acolhem bem. Tu pode ver que aqui têm alguns meninos que ficam mais à margem.

Diferente das meninas, que aparentam viver em relações mais íntimas, os meninos não aparentam segurança em compartilhar assuntos que possam mudar a forma como seus colegas o enxergam. Nascimento (2018, p. 24) denomina "xingamento afetivo" o modo como os meninos se relacionam e demonstram carinho, e coloca que essa dinâmica limita as expressões de afeto nas amizades. Como efeito, meninos são privados de momentos de vulnerabilidade e honestidade emocional, pela necessidade de estarem sempre se provando "homens". Segundo Hacker (1957, p. 228) “entre os elementos que compõe o papel masculino tradicional estão proibidos a admissão e expressão de problemas psicológicos, sentimentos"12, talvez por isso os meninos não estabelecem limites para seus amigos, não dizem 'chega!' para um apelido ou atitude que os magoa.

12 Tradução minha do texto original The New Burdens of Masculinity de Hacker (1957, p. 228). 
Formação de masculinidades: análise das relações presentes em uma turma de escola pública

Outro possível efeito dessa falta de intimidade entre os meninos é não conseguir fazer amizades profundas, que possam compartilhar seus cotidianos e pedir ajuda quando necessário. Porque "qualquer confissão de dúvida, incerteza ou insegurança iria manchar sua imagem, qualquer sinal de fraqueza pode ser tido como feminilidade" 13 (HACKER, 1957, p. 228). Hacker (1957, p. 228) adiciona que "talvez esse seja o maior fardo da masculinidade que nossa cultura impõe"14 pois impele a ausência de contato consigo mesmo, e com outros. A não-presença desses grupos mais íntimos torna o gênero um aglutinador das amizades. Portanto, os meninos são amigos dos meninos pois são meninos, reduzindo a complexidade individual de cada um e tornando-os falsamente homogêneos. Devido os estereótipos das masculinidades, desenvolvem uma variedade de gostos e prazeres muito limitados e definidos pela expectativa de gênero a eles atribuída.

\section{As marcas da masculinidade}

A instituição social escola, aliançada historicamente à igreja, tem sido uma das principais formadoras de humanos que a ela têm acesso. Além de transmitir tradições e reproduzir o contexto social onde se insere, a escola imprime nos corpos as marcas que se transformarão em ideais e comportamentos, individuais e coletivos. Pergunta-se, então: quem seriam os/as sujeitos formados por essa escola que reforça e potencializa uma masculinidade hegemônica? Através das observações e entrevistas, evidenciou-se a marcante desatenção dos meninos em relação aos seus arredores. Parecem ser mais autocentrados que as meninas, sem enxergar o outro. Sobre o porquê de os meninos não desenvolverem amizades, Raquel aponta:

[Raquel] Perceber que aquele colega tá à margem, que aquele colega não tá se entrosando, que aquele colega tá precisando de ajuda, de um acolhimento. Eu acho que eles não conseguem perceber isso.

Essa ausência de identificação com outros/as pode ser um produto da normatização da experiência masculina e branca. As meninas, segundo Raquel, enxergam as novas colegas mesmo que seja para excluí-las. Louro (2013) pontua que a posição central é considerada a posição de sujeito não-problemática, e as outras são subjugadas a esta. Os sentidos são atribuídos por uma lógica que define quem é o centro e quem é excêntrico/a, e que vincula noções de permanência, universalidade, 
estabilidade vinculam-se aos sujeitos centralizados; e instabilidade e diversidade aos excêntricos. Nessa perspectiva, a noção de mutabilidade e provisoriedade só pode se aplicar às mulheres, LGBTs, negros/as, indígenas. Aos homens brancos cabe a identidade confiável, sólida e permanente.

A socialização destes do centro implica em incompreensões frente a outras experiências de vida, tão válidas e relevantes quanto a sua. Louro (2013, p. 44) expressa: "a contínua afirmação e reafirmação deste lugar privilegiado nos faz acreditar em sua universalidade e permanência; nos ajuda a esquecer seu caráter construído e nos leva a conceder a aparência de natural”, o que fortalece a permanência da perspectiva cêntrico/excêntrico. Pedagogicamente, portanto, é necessário evitar reafirmações sobre o já dito, e desensinar o que o corpo/mente dos meninos já assimilou.

Entre os projetos realizados pelas alunas, há um contra o racismo, encabeçado por meninas negras em sua maioria, além de meninas brancas e meninos negros; outro projeto foi um ciclo de conversas sobre bullying na escola, também encabeçado por estes grupos. Professoras relataram que os meninos brancos da turma não se envolvem com esses projetos e que as meninas resistiam mais às normas, posicionando-se quando havia discordâncias com a professora ou direção. Sobre debates em aula, Helena disse:

[Helena] As gurias começam a se posicionar, os meninos não tanto [..] Os meninos ficam quietos, aí largam uma piadinha e já são queimados. Aquelas coisas de guri bobo, imaturo.

As meninas se articulam; organizaram protestos em relação às vestimentas permitidas e até boicote ao pagamento da formatura. Atuam contra as dinâmicas de poder que reforçam padrões conservadores, já estabelecidas na escola. Baseando-se na dualidade poder-resistência, as estudantes tendem a confrontar regras, normas e filosofias implícitas na gestão escolar. A rebeldia e o confronto são quase inevitáveis para as meninas, visto que "para as mulheres, o gênero é uma questão central" (STREY, 2001, p.60). Apropriam-se do lugar de "outro/a", criando significados próprios ao ser "menina" ou "mulher". Assim sendo, representam sujeitos excêntricos à norma, que “não buscam ser 'integrados' [...]; o que desejam é romper com uma lógica que [...] continua se remetendo, sempre, à identidade central" (LOURO 2013, p. 49). Criam alianças entre meninas negras e brancas, meninos negros e alunos LGBT, a fim de exigir espaço de fala em uma instituição reforçadora da hierarquia que subjuga esses mesmos grupos. Ao disputarem as narrativas, estão a "reivindicar sua humanidade" 
Formação de masculinidades: análise das relações presentes em uma turma de escola pública

(RIBEIRO, 2017, p. 90). Pode ser que meninos brancos sintam-se excluídos dessas dinâmicas de alianças por não se afinarem as suas reivindicações.

Uma maneira de resistência dos meninos são os atrasos, vistos como transgressão à ordem imposta e exercício de uma autonomia muito pouco presente no ambiente escolar. Segundo Raquel: "Eles tão aqui então eles têm que se adaptar a essa realidade. E isso pra eles eu acho que é bem complicado". Ademais, apareceu uma relutância na maioria dos meninos em se submeterem ao sistema escolar e os modelos avaliativos. Louro (2000, p.9), apoiada em Foucault, expressa que "historicamente, os sujeitos tornam-se conscientes de seus corpos na medida em que há um investimento disciplinar sobre eles"15. Em relação às resistências das meninas, observou-se mais contraposição das professoras do que às dos meninos, reforçando que a escola atua como vigilante (FOUCAULT, 1999) dos corpos femininos, a fim de neles inscrever o que a sociedade espera que seja ensinado e internalizado por mulheres. Vigiando as meninas, a escola desvia o olhar para longe dos meninos, não enxergando que eles renunciam à sua escolarização para acessar um patamar de masculinidade conflitante com o projeto educacional.

\section{Entre o hoje e o amanhã: as possibilidades}

Distante de querer estabelecer uma narrativa única sobre a formação das masculinidades na escola, e seus efeitos, buscou-se compreender os discretos sentimentos que os meninos deixam escapar através das fissuras em suas armaduras. Admitem-se as limitações da pesquisa e adiciona-se que entrevistar os estudantes seria de enorme valor para criar aproximações mais sensíveis e analíticas sobre o que vivem os meninos. Diversas falas e comportamentos observados incidem na construção de uma masculinidade hegemônica por parte da equipe escolar. Contudo, também explicitou-se uma contraposição das professoras ao status quo em sala de aula e busca por uma educação mais igualitária.

Na turma em foco, o processo de constituição das relações de poder atreladas ao gênero é sutil. É preciso atenção para perceber o que se inscreve nas falas e comportamentos dos estudantes. Além de entender o conturbado caminho pelo qual os meninos sedimentam sua escolarização, é fundamental pensar e agir visando transformações. Para tanto, a escola necessita identificar quais formas de masculinidade

15 Louro cita Foucault, 1993, p.146. 
operam em seu entorno e qual seria o padrão hegemônico que ela mesma constrói (SKELTON, 2001). Refletir sobre qual menino a escola forma - e se há espaço para ele no mundo de hoje - pode ser um caminho na continuidade de pesquisas sobre gênero, sexualidade e masculinidades.

Educar e ensinar os meninos para outra convivência social, que requer novas masculinidades, é indispensável. A crise da masculinidade é a crise dos modos tradicionais de relação entre gêneros, expressos em frases como "homem manda, mulher obedece"; "lugar de mulher é a casa, o de homem é na rua" (SEFFNER, 2017, p. 57). Já não há tanto espaço para masculinidades hegemônicas, que buscam a manutenção das relações de gênero desiguais. Seffner (2017, p. 57) enfatiza que "a crise da masculinidade é fruto da sensação de uma promessa não cumprida. Garotos foram educados com a ideia de que teriam todos os privilégios para si”. Quando na vida adulta, eles percebem que a promessa não condiz com suas expectativas, cria-se frustrações que podem conduzi-los à rejeitar a sociedade como está dada. Esse desapontamento distancia mais os homens brancos do restante da sociedade.

Se a escola ensina a viver em sociedade, talvez seja hora de discutir o que é ser cidadã/ão brasileira/o hoje, incluindo as marcas de diferenças - gênero, classe social, raça, etnia, sexualidade - que compõem o ser humano e são constituintes do tecido social. A sociedade patriarcal criou e difundiu noções relativas ao homem como alguém que não chora, não demonstra sentimentos, não pode ser fraco nem perdedor. Não se pode conceber uma masculinidade fundamentada na "alienação de sentimentos, de afetos" (LYRA, MEDRADO, 2000, p.151), como a almejada para os homens do futuro. A escola deve pensar em outro modelo de masculinidade, que se encaixe em um projeto de futuro mais equitativo, em que as transformações socioeducacionais atuem de modo a constituir meninos e meninas como sujeitos plurais e de mesmo valor social.

Por entender que as reflexões e análises apresentadas se relacionam fortemente com os pressupostos dos Estudos de Gênero e da Educação, já que gênero é um construto ensinado, aprendido e incorporado, intencionou-se identificar, compreender e mapear as configurações binárias e dicotômicas presentes em uma turma de nono ano. Sabendo que muitos homens se agarram à masculinidade tóxica, deitam-se na misoginia e se cobrem com o racismo, é preciso criar outras condições de formação das masculinidades. Nas palavras de Seffner (2017, p. 57) “essa situação de injustiça social acarreta também na produção de masculinidades muito desajustadas, homens levando vidas emocionalmente desequilibradas" (SEFFNER, 2017, p. 57). 
Formação de masculinidades: análise das relações presentes em uma turma de escola pública

Há diversos caminhos a seguir para evitar que a construção das masculinidades na escola siga provocando injustiça social. Estudar, conhecer, divulgar conhecimentos, e repensá-las, é uma tarefa urgente. Aproximações e entendimentos sobre o que vivem meninos escolarizados, e os processos de construção de suas masculinidades, é imprescindível para a busca de novas masculinidades. Validar e dar seguimento ao processo investigativo é um passo na direção de uma sociedade mais diversa e respeitosa.

\section{Referências}

ALVAREZ URÍA, Fernando; VARELA, Julia. Sociología de las instituciones: bases sociales y culturales de la conducta. Madrid: Editorial Morata, 2009. 237 p.

BARDIN, Laurence. Análise de Conteúdo. Tradução: Luís Antero Reto e Augusto Pinheiro. São Paulo/SP: Edições 70, 2011, 229 p.

BOURDIEU, Pierre. A Dominação Masculina. Tradução: Maria Helena Kühner. 11. ed. Rio de Janeiro/RJ: Bertrand Brasil, 2012. 160 p.

BRASIL. Instituto Brasileira de Geografia e Estatística - IBGE. Síntese de indicadores sociais, 2002. Síntese de indicadores sociais confirma as desigualdades da sociedade brasileira. Rio de Janeiro, jun. de 2003. Disponível em:

https://biblioteca.ibge.gov.br/visualizacao/livros/liv1882.pdf. Acesso em: 30 mai. 2020.

BRASIL. Instituto Nacional de Estudos e Pesquisas Educacionais Anísio Teixeira INEP. Síntese e análise de dados do Censo da Educação Superior. Brasília, mar. 2009. Disponível em: http://inep.gov.br/artigo//asset_publisher/B4AQV9zFY7Bv/content/mulheres-estao-em-maior-numero-naeducacao-superior/21206. Acesso em: 30 mai. 2020.

CARNEIRO, Aparecida Sueli. A Construção do outro como não-ser como fundante do ser. 2005.339 p. Tese de doutorado apresentada ao Programa de Pós-Graduação em Educação, Universidade de São Paulo, 2005.

CARRIGAN, Tim; CONNELL, Bob; LEE, John. Toward a new sociology of masculinity. Theory and Society, v.14, n.5, p. 551-604, set. 1985. https://doi.org/10.1007/BF00160017

CARVALHO, Marília Pinto de. Quem são os meninos que fracassam na escola? Cadernos de Pesquisa, São Paulo/SP, v. 34, n.121, p.11-40. jan./abr. 2004.

CARVALHO, Marília Pinto de. Sucesso e fracasso escolar: uma questão de gênero. Educação e Pesquisa, São Paulo/SP, v.29, n.1, p.185-193, jan./jun. 2003.

COMIOTTO, Andressa Barbosa; GUIZZO, Bianca Salazar; Gênero E Sexualidade No Pne (2001-2010): Uma Articulação Possível com a Prática Docente? Revista De Iniciação Científica da Ulbra, Canoas/RS, n. 14, p.122-131, 2016. Disponível em: 
http://www.periodicos.ulbra.br/index.php/ic/article/view/1987/1970 Acesso em 30 mai. 2020

CONNELL, Raewyn; PEARSE, Rebecca. Gênero: Uma perspectiva global. 3 ed. Tradução: Marília Moschkovich. São Paulo: nVersos, 2015. 290 p.

CONNELL, Robert; MESSERSCHIMDT, James. Masculinidade hegemônica: repensando o conceito. Revista Estudos Feministas, Florianópolis/SC, v.21, n.1, p. 241282. jan./abr. 2013.

CONNELL, Robert. Políticas da masculinidade. Educação \& realidade, Porto Alegre/RS, v.20, n.2, p.185-206. jul./dez. 1995.

DATAFOLHA. Mulheres: Violência e Feminismo. Instituto de Pesquisa Datafolha, Opinião Pública, dossiês. São Paulo, abr. de 2019. Disponível em: https://datafolha.folha.uol.com.br/opiniaopublica/2019/04/1987743-38-das-mulheresbrasileiras-se-consideram-feministas.shtml. Acesso em: 27 de maio de 2020.

ESCOSTEGUY, Ana Carolina D. Estudos culturais: uma perspectiva histórica. In: ESCOSTEGUY, Ana Carolina D. Cartografias dos estudos culturais. Belo Horizonte/MG: Autêntica, 2010. p. 27-64. Coleção Estudos Culturais, 8. Disponível em: https://www.academia.edu/8360626/Cartografias_dos_estudos_culturais_uma_vers\%C3 \%A3o_latino-americana. Acesso em: 10 jun.2020.

FELIPE, Jane. Infância, gênero e sexualidade. Educação \& Realidade, Porto Alegre/RS v.25, n.1, p.115-131. jan./jun. 2000.

FOUCAULT, Michel. Vigiar e punir: nascimento da prisão. Tradução: Raquel Ramalhete. 20 ed. Petrópolis/RJ: Vozes, 1999. 288 p.

GODOY, Arilda Schmidt. Introdução à pesquisa qualitativa e suas possibilidades. Revista de Administração de Empresas, São Paulo/SP, v.35, n.2, p.57-63, mar./abr. 1995.

GUIZZO, Bianca Salazar; RIPOLL, Daniela. Gênero e sexualidade na educação básica e na formação de professores: limites e possibilidades. HOLOS, Natal/RN, v. 6, p.472483, dez. 2015. Disponível em:

http://www2.ifrn.edu.br/ojs/index.php/HOLOS/article/view/2945 Acesso em: $21 \mathrm{abr}$. 2020.

GUNDERLOY, Mike. Acronyms, Initialisms \& Abbreviations Dictionary. Volume 1, Part 1. EUA: Gale Research Co, 1989. p.32-36.

HACKER, Helen Mayer. The New Burdens of Masculinity. Marriage and Family Living, v.19, n.3, p.227-233. ago. 1957

HALL, Stuart. A identidade na pós-modernidade. Tradução: Tomaz Tadeu da Silva e Guacira Lopes Louro. 11 ed. Rio de Janeiro/RJ: DP\&A, 2006. p. 102.

LOURO, Guacira Lopes. A construção escolar das diferenças. In: LOURO, Guacira Lopes. Gênero, sexualidade e educação: uma perspectiva pós-estruturalista. 7. ed. Petrópolis/RJ: Vozes, 1997, p. 57-87. 
Formação de masculinidades: análise das relações presentes em uma turma de escola pública

LOURO, Guacira Lopes. Currículo, gênero e sexualidade: o normal, o diferente e o excêntrico. In: LOURO, Guacira Lopes; FELIPE, Jane; GOELLNER, Silvana Vilodre (orgs.). Corpo, gênero e sexualidade: um debate contemporâneo. 9 ed. Petrópolis/RJ: Editora Vozes, 2013, p. 43-53.

LOURO, Guacira Lopes. Pedagogias da sexualidade. In: LOURO, Guacira Lopes. (org.). O corpo educado: pedagogias da sexualidade. 2 ed. Belo Horizonte/MG: Autêntica, 2000, p. 07-34.

LOURO, Guacira Lopes. Segredos e Mentiras do Currículo: sexualidade e gênero nas práticas escolares. In: SILVA, Luiz Heron da (org.). A Escola Cidadã no Contexto da Globalização. Petrópolis/RJ: Vozes, 1998, p.33-47.

LYRA, Jorge; MEDRADO, Benedito. Gênero e paternidade nas pesquisas demográficas: o viés científico. Revista Estudos Feministas, Florianópolis/SC, v.8, n.1, p.145-158, 2000.

MEYER, Dagmar Elisabeth Estermann; KLEIN, Carin; ANDRADE, Sandra dos Santos. Sexualidade, prazeres e vulnerabilidade: implicações educativas. Educação em Revista, Belo Horizonte/MG, n. 46, p. 219-239, dez. 2007.

MEYER, Dagmar Estermann; SOARES, Rosângela de F. Rodrigues. Corpo, Gênero e Sexualidade nas Práticas Escolares: um início de reflexão. In: MEYER, Dagmar Estermann; SOARES, Rosângela de F. Rodrigues (orgs.). Corpo, Gênero e Sexualidade. Porto Alegre/RS: Mediação, 2004, p. 05-16.

MINAYO, Maria C. S. (org). Pesquisa social: teoria, método e criatividade. 21 ed. Petrópolis/RJ: Vozes, 2002. 80 p.

MOREIRA, Marco Antônio. Metodologias de pesquisa em ensino. 1 ed. São Paulo/SP: Livraria da Física, 2011. 242 p.

NASCIMENTO, Marcos. Essa história de ser homem: reflexões afetivo-políticas sobre masculinidades. In: CAETANO, Marcio; SILVA JUNIOR, Paulo Melgaço da (orgs.). De guri a cabra macho: masculinidades no Brasil. Rio de Janeiro/RJ: Lamparina, 2018. Cap 1. p. 16-27.

PEDRO, Joana Maria. Traduzindo o debate: o uso da categoria gênero na pesquisa histórica. História, São Paulo/SP, v.24, n.1, p.77-98, 2005. Disponível em: https://www.scielo.br/pdf/his/v24n1/a04v24n1.pdf Acesso em: 30 mai. 2020.

RIBEIRO, Djamila. O que é lugar de fala? 1 ed. Belo Horizonte/MG: Letramento Editora e Livraria LTDA, 2017. 96 p.

ROSENTHAL, Robert; JACOBSON, Lenore. Pygmalion in the classroom. The urban review, Nova Iorque, v. 3, n. 1, p.16-20, set. 1968.

SANTOS, Boaventura de Sousa. Um discurso sobre as ciências na transição para uma ciência pós-moderna. Estudos Avançados, São Paulo/SP, v.2, n.2, p.46-71, mai./ago. 1998. 
SEFFNER, Fernando. A virilidade vaza, o poder masculino oscila, os homens se inquietam: é crise, é hora de mudar a vida. Caderno Globo 12, Rio de Janeiro: Globo comunicação e participações S.A., p. 54-60, jun. 2017.

SEFFNER, Fernando; DA SILVA, Luciano Ferreira. Canetas coloridas ou mini-skates? coisas de meninas e coisas de meninos na cultura escolar. Métis: história \& cultura, Caxias do Sul/RS, v. 13, n. 26, p. 31-60, jul./dez. 2014.

SEFFNER, Fernando; DA SILVA, Luciano Ferreira. "Mind the trap": o menino, a escola e a folha de alface. Revista Educação, Porto Alegre/RS, v. 39, n. 3, p.393-403, dez. 2016.

SILVA, Cármen A. Duarte; BARROS, Fernando; HALPERN, Sílvia C; SILVA, Luciana A. Duarte da; Meninas bem-comportadas, boas alunas; meninos inteligentes, indisciplinados. Cadernos de Pesquisa, São Paulo/SP, v.29, n.107, p. 207-225, jul. 1999.

SILVA, Natanael de Freitas. Historicizando as masculinidades: considerações e apontamentos à luz de Richard Miskolci e Albuquerque Júnior. História, histórias, Brasília/DF, v. 3, n. 5, p. 7-22, dez. 2015.

SILVA, Tomaz Tadeu da. O adeus às metanarrativas educacionais. In: SILVA, Tomaz Tadeu da (org.). O sujeito da educação: estudos foucaultianos. Petrópolis/RJ: Vozes, 1994, p. 247-258.

SKELTON, Christine. Schooling the boys. Buckingham: Open University Press, 2001. $224 \mathrm{p}$.

STREY, Marlene Neves. Apresentação. In: STREY, Marlene Neves; MÜHLEN, Bruna Krinberg Von; KOHN, Kelly Cristina (orgs.). Caminhos de homens: Gênero e movimentos. Porto Alegre/RS: EDIPUCRS, 2015, p.07-17.

STREY, Marlene Neves. Violência e gênero: um casamento que tem tudo para dar certo. In: GROSSI, Patrícia Krieger (org.). Violências e gênero: coisas que a gente não gostaria de saber. Porto Alegre/RS: EDIPUCRS, 2001. p. 47-69.

WILLIS, Susan. Cotidiano: para começo de conversa. Tradução: Elena Elizabeth Riederer e Guiomar Gimênez Boscov. Rio de Janeiro: Graal, 1997. 230 p

Recebido em junho de 2020.

Aprovado em junho de 2020. 